\title{
erbB2 gene silencing and its effect on PTEN in SACC-83 salivary adenoid cystic carcinoma cells
}

\author{
XIAOHUA LIU ${ }^{1}$, YINCHENG ZHANG ${ }^{1}$, WENHAO REN ${ }^{1}$ and GUOZHOU RAO ${ }^{2}$ \\ ${ }^{1}$ Department of Oral and Maxillofacial Surgery, ${ }^{2}$ Center Research, \\ Stomatology Hospital of Xi'an Jiaotong University, Xi'an, P.R. China
}

Received June 1, 2010; Accepted August 13, 2010

DOI: 10.3892/or_00000985

\begin{abstract}
B2 gene plays an important role in carcinoma formation. erbB2 overexpression was observed in many types of tumours, including salivary carcinoma. However, a putative erbB2 and PTEN interaction remains largely unknown in salivary adenoid cystic carcinoma cells. The purpose of this study was to silence erbB2 gene and investigate the functional relationship between erbB2 and PTEN in SACC-83 salivary adenoid cystic carcinoma cells. erbB2-specific siRNAs were transfected into SACC-83 cells using cationic liposome. RT-PCR, immunocytochemistry and Western blotting were employed to detect erbB2 and PTEN expression. Compared with the control groups, erbB2 mRNA expression was decreased in the erbB2-siRNA transfection group, and immunocytochemistry and Western blotting indicated a concordant erbB2 protein reduction. The average optical density values for erbB2 proteins in erbB2-siRNA transfected group were significantly lower than that in the control groups $(\mathrm{P}<0.05)$. On the other hand, PTEN expression at both mRNA and protein levels were not significantly affected by erbB2 silencing $(\mathrm{P}>0.05)$. In conclusion, the data indicate that siRNA could effectively silence erbB2 gene expression in SACC-83 cells, but PTEN expression appeared unaltered following erbB2 silencing. PTEN expression might not be strictly associated with erbB2 amplification in SACC-83 cells. Future studies will more closely examine the molecular and biological relationships of erbB2 and PTEN in salivary adenoid cystic carcinoma.
\end{abstract}

\section{Introduction}

Salivary adenoid cystic carcinoma (SACC) is a common oral tumour, known to be highly destructive and unpredictable

Correspondence to: Dr Yincheng Zhang, Department of Oral and Maxillofacial Surgery, Stomatology Hospital of Xi'an Jiaotong University, 5th West Road, Xi'an 710004, P.R. China

E-mail: zycxjtu@yahoo.cn

Key words: salivary adenoid cystic carcinoma, siRNA, erbB2, PTEN
(1-3). Previous research has demonstrated a possible role of oncogenic activation in SACC (4-6). erbB2, also called HER2, is a cell surface receptor tyrosine kinase (RTK) and becomes internalized upon ligand binding which can trigger a multitude of signaling pathways, such as MAPKs and PI3K. The erbB family consists of four structurally related tyrosine kinase receptors: erbB1, erbB2, erbB3, and erbB4. These four receptors contain multiple cytosolic tyrosines, which can interact with one or more adaptor proteins to activate downstream signaling pathways when phosphorylated. Furthermore, the erbB receptors display functional redundancy with overlapping signaling pathways. erbB2 is the preferred heterodimerization partner of all erbB proteins, and plays important roles in the lateral transmission of signals between other erbB receptors (7). Consequently, erbB2 has been shown to trigger signal transduction leading to cell growth and differentiation. Tumours showing erbB2 amplification/ overexpression have been shown to demonstrate increased aggressiveness and metastatic potential and decreased overall survival (8-10). In previous studies, erbB2 gene expression was found to be elevated in many types of tumours, including salivary gland carcinoma (11-13).

PTEN is an important tumour suppressor gene located on chromosome 10q23.3. The encoded protein displays homology with the catalytic domain of tyrosine phosphatases, as well as the cytoskeletal proteins tensin and auzilin. PTEN proteins function to dephosphorylate phosphatidyl inositol 3, 4, 5-triphosphate produced by PI3K, thereby acting as a major negative regulator of the PI3K pathway via dual-specificity phosphorylation. PTEN can be deactivated by phosphorylation in various cell types. Upon phosphorylation, PTEN undergoes conformational changes accompanied by loss of activity (14). Impaired PTEN activities have been observed in many tumours $(15,16)$, contributing to tumourigenesis via induction of apoptosis and cell cycle arrest. PTEN also regulates cell adhesion and migration through interactions with focal adhesion kinase. PTEN acts through inhibition of the PI3K/ Akt pathway which promotes cell survival and proliferation (17). The biological function of PTEN is multifaceted, required for the control of cell cycle, cell growth, and apoptosis. PTEN can also be inactivated via gene mutation, loss of mRNA expression, hypermethylation, degradation or posttranslational modification $(18,19)$.

Extensive studies have investigated the functional interaction of PTEN with other genes. However, a putative PTEN 
and erbB2 interaction remains largely unknown. RNA interference (RNAi) is a key mechanism in host defense and gene regulation. Moreover, gene silencing using small interfering RNA (siRNA) has become a powerful approach to probe gene function in mammalian cells (20-22). In the present study, we employed siRNA to silence erbB2 gene expression in the SACC-83 cell line, and to evaluate the effect of erbB2 silencing on PTEN expression.

\section{Materials and methods}

Cell culture. The adenoid cystic carcinoma cell line SACC-83 was obtained from Peking University School of Stomatology (Beijing, China). SACC-83 cells were cultured in RPMI-1640 medium supplemented with $10 \%$ calf-serum and grown in humidified atmosphere at $37^{\circ} \mathrm{C}$ with $5 \% \mathrm{CO}_{2}$. Experiments were performed with cells undergoing logarithmic growth.

siRNA transfection. siRNA target sequences were designed as previously described $(23,24)$. The sequences of $19-21 \mathrm{nt}$ were selected as RNAi target sites based on erbB2 conserved sequences. The BLAST homology search was performed to ensure no significant sequence homology with other human genome sequences. A nonspecific siRNA and a fluorescent siRNA were designed as control. These siRNAs were named erbB2-siRNA, control-siRNA, and FAM control-siRNA, respectively. The sequences were: erbB2-siRNA, sense 5'-GCCUCACAGAGAUCUUGAATT-3', antisense 5'-UUC AAGAUCUCUGUGAGGCTT-3'; control-siRNA, sense 5'-UUCUCCGAACGUGUCACGUTT-3', antisense 5'-ACG UGACACGUUCGGAGAATT-3'; FAM control-siRNA, sense 5'-UUCUCCGAACGUGUCACGUTT-3', antisense 5'-ACGUGACACGUUCGGAGAATT-3'. siRNAs were obtained from Shanghai GenePharma Co., Ltd. (Shanghai, China).

Four experimental groups were designed: blank control group, liposome control group, negative control-siRNA group, and erbB2-siRNA group. SACC-83 cells were grown in six-well plates in $2 \mathrm{ml}$ growth medium without antibiotics for $24 \mathrm{~h}$ before transfection. siRNA-Lipofectamine 2000 (Invitrogen, Carlsbad, CA, USA) complexes were prepared according to the manufacturer's instructions, and used in transfection when cells reached 50-70\% confluence. Lipofectamine $2000(5 \mu 1)$ was added to $200 \mu 1$ of Opti-MEMI reduced serum medium without serum, mixed gently and kept at room temperature for $5 \mathrm{~min}$. Then $5 \mu \mathrm{l}$ of $20 \mu \mathrm{M}$ siRNA was added to $200 \mu 1$ of Opti-MEMI reduced serum medium and mixed gently. The final concentration of siRNA when added to the cells was $50 \mathrm{nM}$. After incubation at room temperature for $5 \mathrm{~min}$, the diluted siRNA and the diluted Lipofectamine 2000 were combined, mixed gently and kept at room temperature for $20 \mathrm{~min}$. The siRNA-Lipofectamine 2000 complexes were added to each well containing cells and medium to a final volume of $2 \mathrm{ml}$ and mixed gently by rocking the plate back and forth. Cells were incubated at $37^{\circ} \mathrm{C}$ in a $\mathrm{CO}_{2}$ incubator. The medium was replaced by complete medium after $6 \mathrm{~h}$. Transfection efficiency was assayed by fluorescence microscopy of cells transfected with FAM control-siRNA for $6 \mathrm{~h}$. Cells were harvested $48 \mathrm{~h}$ posttransfection and erbB2 and PTEN expression were assayed.
$R T-P C R$. Total RNAs were extracted from the transfected SACC-83 cells using TRIzol Reagent (Invitrogen). RNA quality and concentration were analyzed by measuring absorbance at $260 \mathrm{~nm}$ and $280 \mathrm{~nm}$; the $A_{260} / A_{280}$ ratios were in the range of 1.8-2.0. For single-stranded cDNA synthesis, the reverse transcription reaction was performed using the Revertaid First Strand cDNA synthesis kit (Fermentas, Burlington, Canada). The random hexamer primers and RevertAid $^{\mathrm{TM}}$ M-MuLV reverse transcriptase were used with $2.0 \mu \mathrm{g}$ of total RNAs from each sample. Subsequently, PCR was performed by standard methods and GAPDH was amplified as the internal control. The PCR reactions contained cDNA template $2 \mu \mathrm{l}$, forward primer $1 \mu \mathrm{l}$, reverse primer $1 \mu \mathrm{l}$, 2X Taq PCR MasterMix $25 \mu 1$, and $\mathrm{dH}_{2} \mathrm{O}$ with a final volume of $50 \mu \mathrm{l}$. PCR was carried out under the following conditions: the template cDNA was first denatured at $94^{\circ} \mathrm{C}$ for $5 \mathrm{~min}$, followed by 30 cycles of amplification each of $94^{\circ} \mathrm{C}$ for $30 \mathrm{sec}$, $59^{\circ} \mathrm{C}$ for $30 \mathrm{sec}$, and $72^{\circ} \mathrm{C}$ for $30 \mathrm{sec}$. Finally, the reaction was terminated at $72^{\circ} \mathrm{C}$ for $7 \mathrm{~min}$. GAPDH PCR was carried out for 20 cycles. PCR primers were designed according to published work and GenBank (23). The primer sequences were: erbB2, sense 5'-CTGTGCCCGAGTGTGCTA-3', antisense 5'-GTCCCCATCAAAGCTCTCC-3'; PTEN, sense 5'-TAGAGCGTGCAGATAATGACAAGGA-3', antisense 5'-TGAACTGCTAGCCTCTGGATTTGA-3'; The housekeeping gene GAPDH, sense 5'-GCACCGTCAAGGCTGA GAAC-3', antisense 5'-TGGTGAAGACGCCAGTGGA-3'. The primers were synthesized commercially (Sangon Biotech Co., Ltd. Shanghai, China). All results were confirmed in five independent PCRs. After amplification, PCR products were electrophoresed on a $2 \%(\mathrm{w} / \mathrm{v})$ agarose gel and visualized by ethidium bromide staining to identify the amplified product of the expected size. For semi-quantification, an image of the gel was captured, and the intensity of the bands was quantified using the GeneTools from Syngene gel analysis system.

Immunocytochemical analysis. Anti-erbB2 and anti-PTEN antibodies were rabbit polyclonal antibodies, and the secondary antibody was goat anti-rabbit antibody (Beijing Boisynthesis Biotechnology Co., Ltd., Beijing, China). SACC-83 cells were seeded on glass coverslips. Cells were fixed with $4 \%(\mathrm{v} / \mathrm{v})$ formaldehyde for $30 \mathrm{~min}$ at $4^{\circ} \mathrm{C}$ and rinsed 3 times with PBS. Immunocytochemistry assay was performed according to the manufacturer's protocol. The antibodies were diluted to 1:200 in PBS. The seeded slides were incubated at $4^{\circ} \mathrm{C}$ with primary antibody overnight. On the following day, the slides were rinsed in $\mathrm{PBS}$ and incubated at room temperature with secondary antibody for $10 \mathrm{~min}$. The cells were stained with 3,3'-diaminobenzidine (DAB). The immunoreactivity was detected with a light microscope.

Western blot analysis. The infected SACC-83 cells were harvested. Total cellular proteins were extracted and separated by $8 \%$ SDS-polyacrylamide gel electrophoresis. Subsequently, the proteins were transferred onto nitrocellulose membranes. The membranes were blocked by TBST with non-fat milk for $1 \mathrm{~h}$ at room temperature. The membranes were washed and incubated with the primary antibodies for anti-erbB2, antiPTEN, and anti-GAPDH (Beijing Boisynthesis Biotechnology Co.) for $2 \mathrm{~h}$, followed by incubation with secondary antibodies 


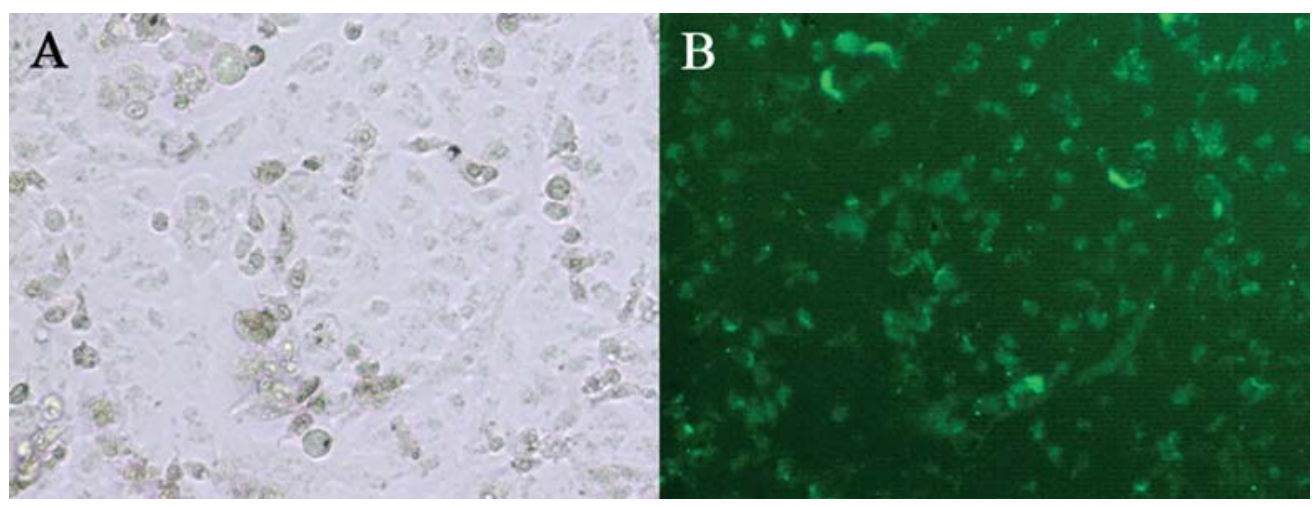

Figure 1. Transfection efficiency of siRNA. Following FAM control siRNAs were transfected, SACC-83 cells were observed via light microscope field (A) or fluorescent microscope field (B). The siRNA was transfected successfully.
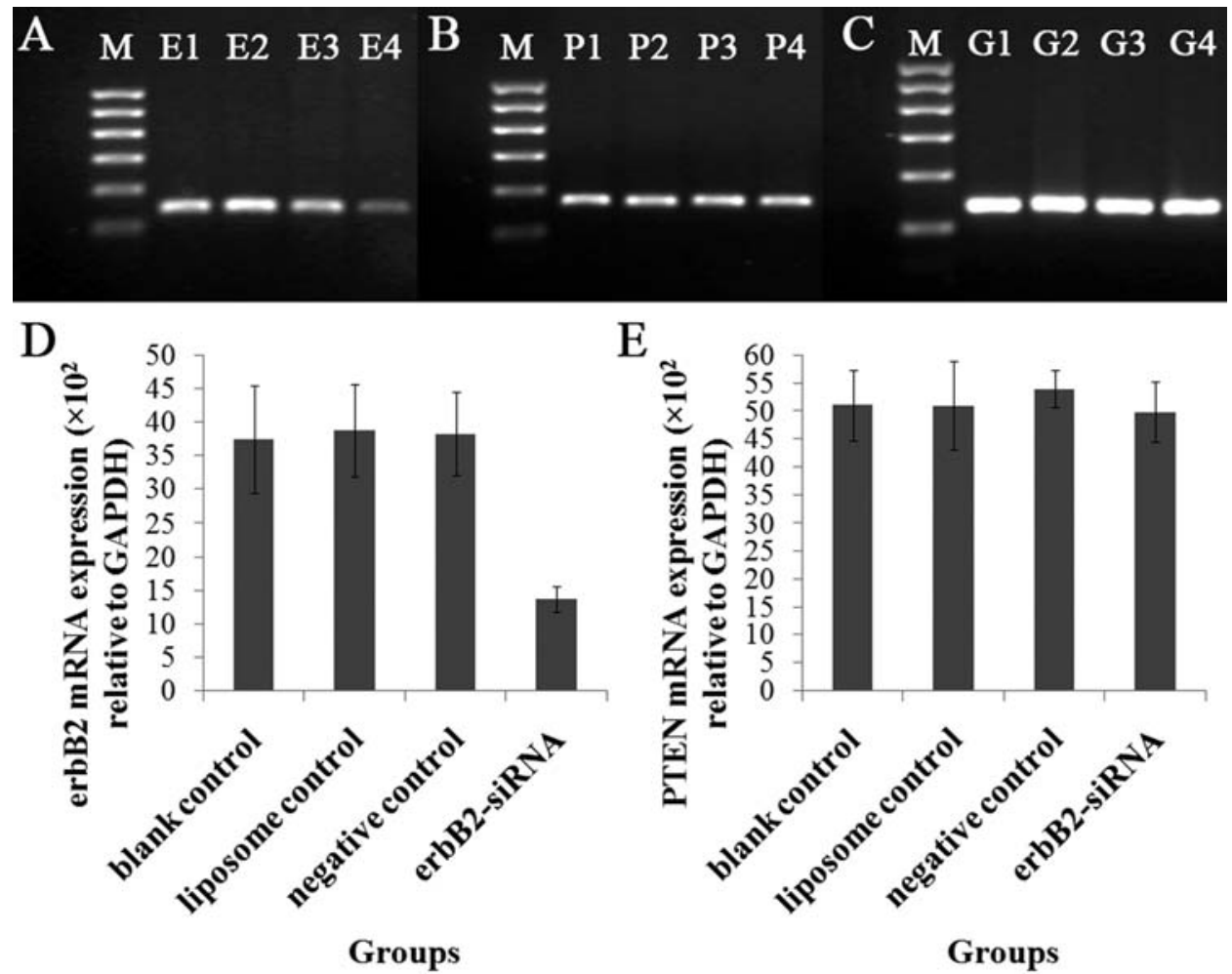

Figure 2. RT-PCR analysis of mRNA expression. The erbB2, PTEN, and GAPDH mRNA expression in the blank control group (E1, P1, G1), the liposome control group (E2, P2, G2), the negative control-siRNA group (E3, P3, G3), and the erbB2-siRNA group (E4, P4, G4), respectively. The results shown the mRNA of erbB2 was decreased in erbB2-siRNA tansfection group (A). The mRNA level of PTEN was not different among groups (B). The mRNA levels of erbB2 (D) and PTEN (E) were relative to GAPDH.

for $1 \mathrm{~h}$. GAPDH was used as an internal control. Gel bands were detected with ECL.

Statistical analysis. For all measurements as needed, the statistical significance between groups was assessed by OneWay ANOVA or Kruskal-Wallis H-test based on homogeneity of variance test (SPSS 13.0, USA). $\mathrm{P}<0.05$ was considered as statistically significant.

\section{Results}

siRNA transfection efficiency. The transfection efficiency was assayed by fluorescence microscopy after cells were transfected by FAM control-siRNA for $6 \mathrm{~h}$. A robust transfection efficiency of $87 \%$ was observed (Fig. 1).

mRNA expression of erbB2 and PTEN. Following siRNA transfection of SACC-83 cells, the mRNA expression of erbB2 and PTEN was examined by RT-PCR. The PCR products were analyzed by electrophoresis on a $2 \%$ agarose gel, and the expected size was observed. erbB2 expression amplification was detected in SACC-83 cells. Importantly, erbB2-siRNA transfected cells exhibited significantly lower erbB2 mRNA expression compared with that of the blank control group, liposome control group, and negative controlsiRNA group (Fig. 2). There was significant difference 

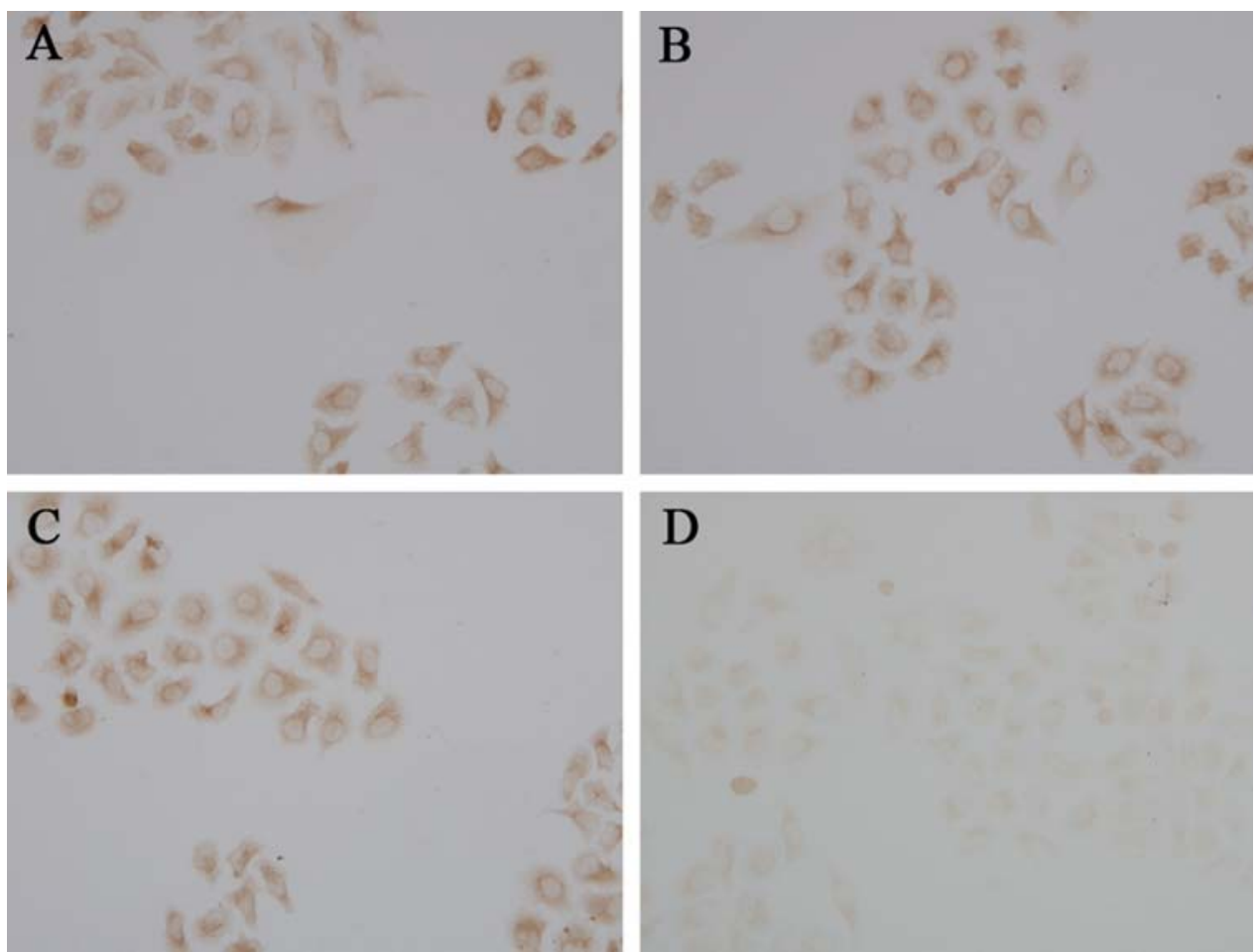

Figure 3. Immunocytochemistry of erbB2 in the blank control group (A), the liposome control group (B), the negative control-siRNA group (C), and the erbB2-siRNA group (D). The SACC-83 cells showed lower level of brown immunostaining in siRNA transfected cells than that in controls.
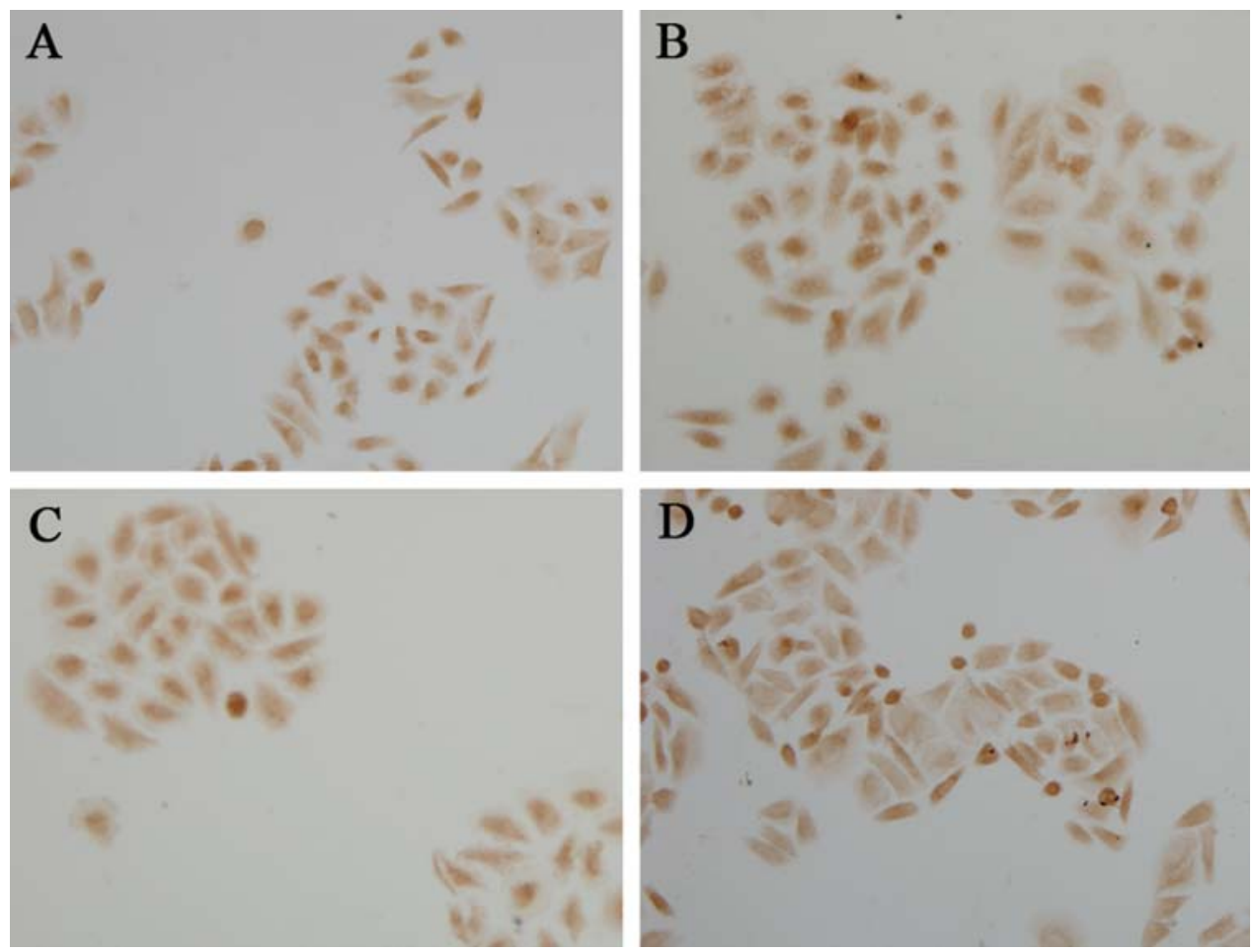

Figure 4. Immunocytochemistry of PTEN in the blank control group (A), the liposome control group (B), the negative control-siRNA group (C), and the erbB2-siRNA group (D). The SACC-83 cells showed brown immunostaining that was not different among groups.

between the silenced cells and control cells $(\mathrm{P}<0.05)$, estimated to be reduction in expression. Therefore, the expression of erbB2 mRNA in SACC-83 cells was knocked down successfully (Fig. 2A). On the other hand, the expression of
erbB2 mRNA showed no significant difference among control groups $(\mathrm{P}>0.05)$. As shown in Fig. 2, the expression of PTEN mRNA was not affected following erbB2 knockdown, with equivalent expression of PTEN mRNA in erbB2 


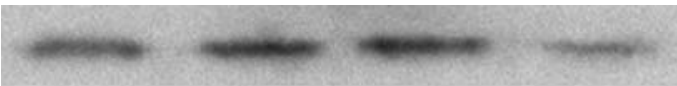

erbB2

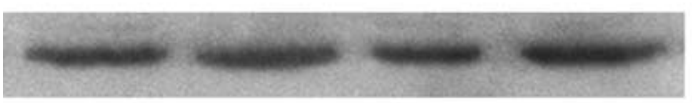

PTEN

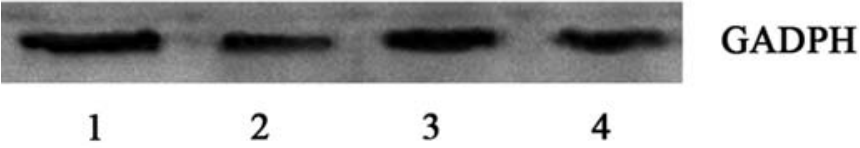

Figure 5. The protein expression of erbB2 and PTEN in the blank control group (1), the liposome control group (2), the negative control-siRNA group (3), and the erbB2-siRNA group (4). The protein level of erbB2 was decreased in erbB2-siRNA transfected cells, and the protein levels of PTEN were not different among groups. It was in accord with the mRNA levels.

silenced cells and control cells (Fig. 2B). No significant differences between groups were observed $(\mathrm{P}>0.05)$.

erbB2 and PTEN protein expression. Immunocytochemical staining of protein was analysed by Image-ProPlus software (Media Cybernetics, USA). The gray scale of the stained area was measured under identical conditions. The average optical density for erbB2 protein expression in the erbB2-siRNA transfection group was lower compared with the value in the blank control group, the liposome control group, and the negative control-siRNA group, respectively. It indicated marked reduction in erbB2 protein following erbB2-siRNA transfection. The observed differences were significant $(\mathrm{P}<0.05)$ (Fig. 3). Consistent with the above mRNA result, the average optical density for PTEN protein expression in the blank control group, the liposome control group, the negative control-siRNA group, and the erbB2-siRNA group showed no significant differences between groups $(\mathrm{P}>0.05)$ (Fig. 4). The protein expression of erbB2 and PTEN were evaluated by Western blotting. The results were in accord with the mRNA levels (Fig. 5).

\section{Discussion}

This study confirmed the power of in vitro RNAi knockdown of erbB2 in SACC-83 cells. erbB receptors, especially of erbB2, play an important role in carcinoma formation, and its dysfunction promotes tumourigenesis. Overexpression of the erbB2 gene was frequently observed in human tumours, including those of breast, lung, stomach, and oral cavity (25-27). Capable of stable and highly specific silencing of gene expression, siRNAs have been extensively applied to silence abnormal gene expression in the treatment of cancer (28). Given that erbB2 was found to be overexpressed in SACC $(11,12)$, we wished to examine the functional consequence of erbB2 silencing in SACC-83 cells. In the present study, after erbB2-siRNA was transfected into the SACC-83 adenoid cystic carcinoma cells, erbB2 expression were significantly reduced at both mRNA and protein levels. Since erbB family mediated signaling played a critical role in cell growth, survival, adhesion, and motility (9), our data suggest that erbB2 gene is a feasible RNAi target for gene silencing therapy against salivary adenoid cystic carcinoma.
Few studies have examined the functional relationship of PTEN and erbB2 in SACC. In this study, we investigated the relationship between erbB2 and PTEN, specifically in SACC-83 cells. PTEN expression was examined following siRNA-mediated silencing of erbB2 gene in SACC-83 cells. We found that silencing of erbB2 did not induce changes in PTEN expression. Although PTEN and erbB2 both contribute to the progression of certain tumours, our data suggest that PTEN expression might not be strictly associated with erbB2 amplification in SACC.

In addition to expression regulation, PTEN might be regulated at multiple levels, such as mutation, loss of heterozygosity, promoter methylation, or activation of alternative signaling pathway. Several studies have shown synergistic effects of PTEN with other genes during tumourigenesis $(29,30)$. On the other hand, there was also evidence that PTEN was not involved in tumour progression (31-33). Chen et al suggested that homozygous deletion of PTEN gene was unlikely to be a feature of oral squamous cell carcinoma, and speculated that cancerous growths from different tissues may have multiple means by PTEN inactivated (34). Another study has investigated PTEN mutation in ovarian cancers, and their results shown that PTEN mutation was not observed in primary ovarian cancers or ovarian cancer cell lines (35). Furthermore, siRNA knockdown of PTEN in erbB2 overexpressing breast cancer cells demonstrated robust responses of breast cancer patients to lapatinib monotherapy regardless of PTEN status (36). Overall, PTEN, a dual phosphatase which appears to play an important role in PI3K/Akt mediated anti-tumour signaling. In SACC-83 cells, however, PTEN and erbB2 expression appears independently regulated.

In summary, we demonstrated that erbB2 was effectively silenced in SACC cells via siRNA knockdown, providing proof of principle for using RNAi in trial protocol to investigate erbB2 biological function in SACC. Furthermore, the expression of PTEN was not altered following erbB2 silencing. Future studies will be required to examine the molecular and biological relationship of erbB2 and PTEN in SACC in greater detail.

\section{References}

1. Khafif A, Anavi Y, Haviv J, Fienmesser R, Calderon S and Marshak G: Adenoid cystic carcinoma of the salivary glands: a 20-year review with long-term follow-up. Ear Nose Throat J 84: 662: 664-667, 2005.

2. Bonaparte JP, Hart R, Trites J and Taylor MS: Incidence of adenoid cystic carcinoma in Nova Scotia: 30-year populationbased epidemiologic study. J Otolaryngol Head Neck Surg 37: 642-648, 2008

3. Tian Z, Li L, Wang L, Hu Y and Li J: Salivary gland neoplasms in oral and maxillofacial regions: a 23-year retrospective study of 6982 cases in an eastern Chinese population. Int J Oral Maxillofac Surg 39: 235-242, 2009.

4. Mantesso A, Loducca SV, Bendit I, Garicochea B, Nunes FD and de Araujo VC: Mdm2 mRNA expression in salivary gland tumour cell lines. J Oral Pathol Med 33: 96-101, 2004.

5. Freier K, Flechtenmacher C, Walch A, et al: Copy number gains on 22 q13 in adenoid cystic carcinoma of the salivary gland revealed by comparative genomic hybridization and tissue microarray analysis. Cancer Genet Cytogenet 159: 89-95, 2005.

6. Sequeiros-Santiago G, Garcia-Carracedo D, Fresno MF, Suarez C, Rodrigo JP and Gonzalez MV: Oncogene amplification pattern in adenoid cystic carcinoma of the salivary glands. Oncol Rep 21: 1215-1222, 2009. 
7. Graus-Porta D, Beerli RR, Daly JM and Hynes NE: ErbB-2, the preferred heterodimerization partner of all ErbB receptors, is a mediator of lateral signaling. EMBO J 16: 1647-1655, 1997.

8. Slamon DJ, Clark GM, Wong SG, Levin WJ, Ullrich A and McGuire WL: Human breast cancer: correlation of relapse and survival with amplification of the HER-2/neu oncogene. Science 235: 177-182, 1987

9. Menard S, Casalini P, Campiglio M, Pupa SM and Tagliabue E: Role of HER2/neu in tumor progression and therapy. Cell Mol Life Sci 61: 2965-2978, 2004.

10. Coronado Martin PJ, Fasero Laiz M, Garcia Santos J, Ramirez Mena M and Vidart Aragon JA: Overexpression and prognostic value of p53 and HER2/neu proteins in benign ovarian tissue and in ovarian cancer. Med Clin (Barc) 128: 1-6, 2007.

11. Press MF, Pike MC, Hung G, et al: Amplification and overexpression of HER-2/neu in carcinomas of the salivary gland: correlation with poor prognosis. Cancer Res 54: 5675-5682, 1994.

12. Sun H, Wu S and Ouyang J: Expression of C-erbB-2 oncogene mRNA in salivary gland tumors. Zhonghua Kou Qiang Yi Xue Za Zhi 34: 289-291, 1999.

13. Nagler RM, Kerner H, Ben-Eliezer S, Minkov I and Ben-Itzhak O: Prognostic role of apoptotic, Bcl-2, c-erbB-2 and p53 tumor markers in salivary gland malignancies. Oncology 64: 389-398, 2003.

14. Vazquez F, Ramaswamy S, Nakamura N and Sellers WR: Phosphorylation of the PTEN tail regulates protein stability and function. Mol Cell Biol 20: 5010-5018, 2000.

15. Colakoglu T, Yildirim S, Kayaselcuk F, et al: Clinicopathological significance of PTEN loss and the phospho-inositide 3kinase/Akt pathway in sporadic colorectal neoplasms: is PTEN loss predictor of local recurrence? Am J Surg 195: 719-725, 2008

16. Yang XF, Xin Y and Mao LL: Clinicopathological significance of PTEN and Caspase-3 expressions in breast cancer. Chin Med Sci J 23: 95-102, 2008.

17. He L, Fan C, Gillis A, et al: Co-existence of high levels of the PTEN protein with enhanced Akt activation in renal cell carcinoma. Biochim Biophys Acta 1772: 1134-1142, 2007.

18. Chow LM and Baker SJ: PTEN function in normal and neoplastic growth. Cancer Lett 241: 184-196, 2006.

19. Gericke A, Munson M and Ross AH: Regulation of the PTEN phosphatase. Gene 374: 1-9, 2006.

20. Elbashir SM, Lendeckel W and Tuschl T: RNA interference is mediated by 21- and 22-nucleotide RNAs. Genes Dev 15: 188-200, 2001

21. Potenza N, Moggio L, Milano G, et al: RNA Interference in mammalia cells by RNA-3'-PNA chimeras. Int J Mol Sci 9: 299-315, 2008

22. Chang $\mathrm{Y}$ and $\mathrm{Wu} \mathrm{XY}$ : JNK1/2 siRNA inhibits transforming growth factor-beta1-induced connective tissue growth factor expression and fibrotic function in THSFs. Mol Cell Biochem 335: 83-89, 2010.
23. Kao J and Pollack JR: RNA interference-based functional dissection of the $17 q 12$ amplicon in breast cancer reveals contribution of coamplified genes. Genes Chromosomes Cancer 45: 761-769, 2006

24. Siomi MC, Nishida KM and Siomi H: Chapter 16. How to define targets for small guide RNAs in RNA silencing: a biochemical approach. Methods Enzymol 449: 345-355, 2008.

25. Verri E, Guglielmini P, Puntoni M, et al: HER2/neu oncoprotein overexpression in epithelial ovarian cancer: evaluation of its prevalence and prognostic significance. Clinical study. Oncology 68: 154-161, 2005 .

26. Nalwoga $H$, Odida $M$ and Wabinga $H$ : c-erbB-2 oncoprotein over-expression in breast cancer and its relationship to histology and grade in a Ugandan population. East Afr Med J 83: 411-415, 2006.

27. Cornolti G, Ungari M, Morassi ML, et al: Amplification and overexpression of HER2/neu gene and HER2/neu protein in salivary duct carcinoma of the parotid gland. Arch Otolaryngol Head Neck Surg 133: 1031-1036, 2007.

28. Gartel AL and Kandel ES: RNA interference in cancer. Biomol Eng 23: 17-34, 2006.

29. Rodriguez OC, Lai EW, Vissapragada $\mathrm{S}$, et al: A reduction in Pten tumor suppressor activity promotes ErbB-2-induced mouse prostate adenocarcinoma formation through the activation of signaling cascades downstream of PDK1. Am J Pathol 174: 2051-2060, 2009

30. Kim TH, Wang J, Lee KY, et al: The synergistic effect of conditional Pten loss and oncogenic K-ras mutation on endometrial cancer development occurs via decreased progesterone receptor action. J Oncol (In press) doi: 10.1155/2010/139087.

31. Dong JT, Sipe TW, Hyytinen ER, et al: PTEN/MMAC1 is infrequently mutated in pT2 and pT3 carcinomas of the prostate. Oncogene 17: 1979-1982, 1998.

32. Kappes H, Goemann C, Bamberger AM, Loning T and MildeLangosch K: PTEN expression in breast and endometrial cancer: correlations with steroid hormone receptor status. Pathobiology 69: 136-142, 2001.

33. Gori S, Sidoni A, Colozza M, et al: EGFR, pMAPK, pAkt and PTEN status by immunohistochemistry: correlation with clinical outcome in HER2-positive metastatic breast cancer patients treated with trastuzumab. Ann Oncol 20: 648-654, 2009.

34. Chen Q, Samaranayake LP, Zhou H and Xiao L: Homozygous deletion of the PTEN tumor-suppressor gene is not a feature in oral squamous cell carcinoma. Oral Oncol 36: 95-99, 2000.

35. Maxwell GL, Risinger JI, Tong B, et al: Mutation of the PTEN tumor suppressor gene is not a feature of ovarian cancers. Gynecol Oncol 70: 13-16, 1998.

36. Xia W, Husain I, Liu L, et al: Lapatinib antitumor activity is not dependent upon phosphatase and tensin homologue deleted on chromosome 10 in ErbB2-overexpressing breast cancers. Cancer Res 67: 1170-1175, 2007. 